\title{
Chemotherapy-induced nausea and vomiting (CINV) in patients with advanced lung cancer during the first-line treatment: assessment by physicians, nurses, and patients from an Italian multicenter survey
}

\author{
S. Carnio ${ }^{1}$ (D) D. Galetta ${ }^{2} \cdot$ V. Scotti ${ }^{3} \cdot$ D. L. Cortinovis ${ }^{4} \cdot$ A. Antonuzzo $^{5} \cdot$ S. Pisconti ${ }^{6} \cdot$ A. Rossi $^{7} \cdot$ O. Martelli $^{8}$.

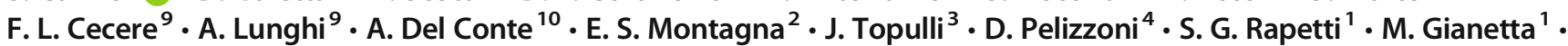 \\ M. V. Pacchiana ${ }^{1} \cdot$ V. Pegoraro ${ }^{11} \cdot$ N. Cataldo ${ }^{11} \cdot$ E. Bria ${ }^{12} \cdot$ S. Novello ${ }^{1}$
}

Received: 9 January 2017 / Accepted: 5 December 2017 / Published online: 21 December 2017

(C) Springer-Verlag GmbH Germany, part of Springer Nature 2017

\begin{abstract}
Purpose Chemotherapy-induced nausea and vomiting (CINV) still represents a common side-effect of chemotherapy, and often, its perception differs between patients and healthcare professionals. The aim of this study was to evaluate the agreement on the perception of CINV and other items among clinicians, patients, and nurses.

Methods This observational prospective study was part of an evaluation program promoted by the Women Against Lung Cancer in Europe (WALCE) Onlus. From August 2015 to February 2016, a survey was administered in 11 oncologic institutions to 188 stage IV lung cancer patients and to their oncologists and nurses during first-line chemotherapy. Our survey investigated 11 aspects: anxiety, mood, weakness, appetite, nausea, vomiting, pain, drowsiness, breath, general condition, and trust in treatments. These items were assessed through Numerical Rating Scale at four consecutive evaluations: at T0 (immediately prior to the first cycle), at T1 (immediately prior to the second cycle), at T2 (immediately prior to the third cycle), and at T3 (immediately prior to the fourth cycle). Clinician versus patient ( $\mathrm{CvP})$, nurse versus patient $(\mathrm{NvP})$, and clinician versus nurse $(\mathrm{CvN})$ agreements were estimated applying Weighted Cohen's kappa. A multivariate logistic model and generalized equation estimates were applied to evaluate factors possibly influencing CINV development.

Results The incidence of patients reporting CINV varied from $40 \%$ at $\mathrm{T} 0$ to $71 \%$ at $\mathrm{T} 3$. Both $\mathrm{CvP}$ and NvP agreement on the investigated items were mainly moderate, slightly increasing over time, and becoming substantial for some items, in particular for NvP. Pre-chemotherapy anxiety in its mild, moderate, and severe manifestations, as well as mild, moderate, and severe anxiety experienced after chemotherapy start, exposed patients to a higher risk of anticipatory and acute/ delayed CINV, respectively.
\end{abstract}

Electronic supplementary material The online version of this article (https://doi.org/10.1007/s00520-017-4004-1) contains supplementary material, which is available to authorized users.

S. Carnio

simona.carnio@libero.it

1 Thoracic Oncology Unit, San Luigi Hospital, University of Turin, Regione Gonzole 10, Orbassano, Turin, Italy

2 Clinical Cancer Center "Giovanni Paolo II", Bari, Italy

3 Department of Oncology Radiation Therapy Unit, Careggi University Hospital, Florence, Italy

4 Medical Oncology Unit, San Gerardo Hospital, Monza, Italy

5 Division of Medical Oncology Department of Oncology, S. Chiara University Hospital, Pisa, Italy
6 Department of OncoEmatology Medical Oncology, SG Moscati Hospital, Taranto, Italy

7 Division of Medical Oncology, SG Moscati Hospital, Avellino, Italy

8 Medical Oncology Unit, San Giovanni Addolorata Hospital, Rome, Italy

9 Department of Oncology, Medical Oncology Unit, Careggi University Hospital, Florence, Italy

10 Department of Medical Oncology, Azienda per l'Assistenza Sanitaria No.5, Friuli Occidentale, Presidio Ospedaliero di Pordenone, Pordenone, Italy

11 Quintiles IMS, Milan, Italy

12 Medical Oncology, Department of Medicine, Verona, Italy 
Conclusions Despite clinical staff awareness of patients' status and perceptions, CINV still represents a clinical problem. This study confirms that particular attention should be paid to anxiety due to its key role in CINV development.

Keywords Chemotherapy-induced nausea and vomiting $\cdot$ Lung cancer $\cdot$ First-line treatment $\cdot$ Anxiety

\section{Background}

Nausea is defined as the unpleasant feeling causing the desire to vomit and can be accompanied by symptoms such as tachycardia, dizziness, and weakness. Vomiting is defined as the contraction of the muscles of the abdomen and diaphragm that triggers the expulsion of stomach contents. Chemotherapyinduced nausea and vomiting (CINV) is a particularly distressing event for oncology patients, both from a physical and psychological perspective [1].

Despite significant progresses in its prevention and control, CINV is still representing an unmet need in the oncology field. A study conducted in 14 centers and six countries showed that around 35 and $60 \%$ of patients experienced acute and delayed CINV, respectively [2].

CINV perception often differs between patients and healthcare professionals. In fact, it has been estimated that $75 \%$ of the healthcare professionals underestimate CINV incidence and severity [3], with these differences representing a perceptual gap between patients and physicians/nurses who care for them. Even if not life-threatening, CINV can influence patients' willingness to continue chemotherapy, thus impacting survival outcomes and quality of life (QoL) [1]. A systematic review by Sommariva et al. showed that CINV has a negative influence on health-related QoL also among patients receiving moderately emetogenic chemotherapy (MEC). The worsening of QoL in oncological adult patients due to emesis has been measured by several studies emphasizing the importance of early prevention and good management of CINV [1].

The 2016 update of Antiemetic Guidelines developed by the Multinational Association for Supportive Care in Cancer (MASCC) and the European Society of Medical Oncology (ESMO) recommends the administration of a 5-HT3 receptor antagonist in combination with dexamethasone and a NK1 receptor antagonist for the prevention of acute CINV in patients treated with highly emetogenic chemotherapy (HEC). For patients receiving a moderately emetogenic chemotherapy (MEC), a combination of a 5-HT3 receptor antagonist and dexamethasone is recommended, except for subjects treated with carboplatin-based chemotherapy, that should be administered with the same combination adopted for HEC. Guidelines also state that the best approach for the prevention of anticipatory CINV is the best possible control of acute and delayed CINV [4].
Despite these recommendations, adherence to the prophylaxis of emesis in Europe is very low and this significantly correlates with the lack of CINV control [5].

Together with chemotherapy's emetogenicity, a number of variables have been implicated in the development of CINV, including female gender, younger age, history of nausea/ vomiting, and anxiety [6]. The aim of this study was to evaluate the degree of agreement among clinicians, patients, and nurses on the perception of CINV and other relevant items and to understand whether anxiety and other demographic and treatment-related factors could play a role in CINV development.

\section{Patients and methods}

This observational prospective study was part of an evaluation program promoted by the Women Against Lung Cancer in Europe (WALCE) Onlus. WALCE Onlus is a European advocacy group devoted to lung cancer patients and their families. Questionnaires were developed in agreement with a psychologist and advocates (please see Appendixes 1, 2, and 3 for further details). Eleven Italian oncologic institutions with strong expertise on lung cancer's treatment and collaborating with WALCE in awareness and patient support programs were the participating centers. For each center, a dedicated physician and a dedicated nurse were identified as representatives. The first inclusion criterion was the application of international guidelines for antiemetics in oncology [7]. From August 2015 to February 2016, stage IV non-small cell lung cancer (NSCLC) and small cell lung cancer (SCLC) patients referring to these centers and their oncologists and nurses took part to the survey. Three different questionnaires were administered to patients, oncologists, and nurses at four consecutive evaluations (T0, T1, T2, and T3) during first-line chemotherapy, immediately before chemotherapy administration. Patients included had to be 18 years older, chemotherapy-naïve, and eligible for MEC or HEC. Questionnaires investigated 11 chemotherapy-related aspects (anxiety, mood, weakness, appetite, nausea, vomiting, pain, drowsiness, breath, general condition, and trust in treatments) as perceived by patients, oncologists, and nurses, by means of a Numerical Rating Scale (NRS) ranging from 0 to 10 . Oncologist's questionnaire also collected information on patients' demographic characteristics, clinical features, and antiemetic therapy. 


\section{Statistical analysis}

Descriptive statistics were used to provide an overview on patients' demographic and clinical characteristics and on treatments. Clinician versus patient $(\mathrm{CvP})$, nurse versus patient $(\mathrm{NvP})$, and clinician versus nurse $(\mathrm{CvN})$ agreements were estimated in relation with the investigated items applying Weighted Cohen's kappa and the grid of Landis and Koch. Weighted kappa coefficients were considered as poor, slight, fair, moderate, substantial, and almost perfect according to Landis and Koch [8].

CINV occurrence was defined as a rating greater than zero assigned to the item nausea and/or a rating greater than 0 assigned to the item vomiting. Presence of anxiety was defined as a rating greater than zero assigned to the respective item, with anxiety level defined as mild when the rating was included in the range 1-3, moderate when ranging from 4 to 7 , and severe when comprised in the range from 8 to 10 .

A multivariate logistic model was performed to evaluate factors possibly influencing anticipatory CINV as perceived by patients: the response variable was the occurrence of anticipatory CINV before the first chemotherapy cycle (T0) based on patients' ratings; the covariates included were age, gender, and anxiety level. Generalized equation estimates (GEE) for repeated measures were used to evaluate factors possibly influencing CINV development overall once first cycle of chemotherapy had been already administered. Response variable was the presence/absence of CINV as perceived by patients at T1, T2, and T3, with GEE for repeated measures accounting for intra-subject correlation. The covariates considered were age, sex, anxiety level at each cycle subsequent to the first one, anxiety level before the first chemotherapy cycle, the chemotherapy scheme, and presence/absence of anticipatory CINV. Odds ratios (ORs) and weighted Kappa coefficients were reported together with their $95 \%$ confidence intervals (95\% CIs).

\section{Results}

One hundred eighty-eight patients completed the questionnaire at T0, 164 at T1, 138 at T2, and 101 at T3. Duly compiled questionnaires accounted for 99\%. Patients' mean age was around 65 years and men accounted for more than $70 \%$ of the patients. Adenocarcinoma was the most represented histological form, followed by squamous cell carcinoma and small cell carcinoma. Cisplatin was administered to 99 (53\%) patients and carboplatin to 86 (46\%). Among patients undergoing cisplatin-based chemotherapy, those prescribed with both 5-HT3 and NK1 antagonist and those prescribed with 5-HT3 antagonist only accounted for about 83 and $13 \%$ at T0, respectively. Among patients undergoing carboplatin-based chemotherapy, those prescribed with both 5-HT3 and NK1 antagonist and those prescribed with 5-HT3 antagonist accounted for about 13 and $86 \%$, respectively (Table 1). When considering the following cycles, the proportion of patients treated with both 5-HT3 and NK1 antagonist and with 5-HT3 antagonists only among those undergoing cisplatinbased chemotherapy did not vary; differently, when focusing on carboplatin-based chemotherapy patients, proportions of those treated with the combination increased over time (data not shown). All CINV prevention regimens were assumed to include steroids as by MASCC/ESMO guidelines [4].

The use of concomitant drugs was evaluated at each assessment. The drugs most frequently used were strong and weak opioids, antidepressants, neuroleptics, and antipsychotics. In particular, 37, 39, 32, and 32\% of the patients assumed weak opioids at $\mathrm{T} 0, \mathrm{~T} 1, \mathrm{~T} 2$, and $\mathrm{T} 3$, respectively; strong opioids were used by $34,27,30$, and $27 \%$ of the patients at $\mathrm{T} 0, \mathrm{~T} 1$, $\mathrm{T} 2$, and T3, respectively. No correlation was observed between the use of opioids and the occurrence of CINV.

Patients who reported anticipatory nausea, anticipatory vomiting, and anticipatory CINV accounted for 39, 21, and $40 \%$, respectively. Proportions of patients experiencing anticipatory CINV were higher among women and patients 50 years younger. At T1 (first cycle), $68 \%$ of the patients experienced nausea, $38 \%$ vomiting, and $68 \% \mathrm{CINV}$, with

Table 1 Patients' characteristics at T0

Total number of patients, 188

\begin{tabular}{|c|c|c|c|}
\hline Gender & $N(\%)$ & & \\
\hline Male & $134(71)$ & & \\
\hline Female & $54(29)$ & & \\
\hline $\begin{array}{l}\text { Age (mean } 64.6 ; \mathrm{SD} \\
\quad 8.4 ; \min 41.0 ; \max 83.0)\end{array}$ & $N(\%)$ & & \\
\hline $40-50$ & $13(7)$ & & \\
\hline $50-60$ & $32(17)$ & & \\
\hline $60-70$ & $92(49)$ & & \\
\hline$>70$ & $51(27)$ & & \\
\hline Histological form & $N(\%)$ & & \\
\hline Adenocarcinoma & $114(61)$ & & \\
\hline Squamous carcinoma & $36(19)$ & & \\
\hline Small cells carcinoma & $30(16)$ & & \\
\hline $\begin{array}{l}\text { Poorly differentiated } \\
\text { carcinoma }\end{array}$ & $7(4)$ & & \\
\hline Other & $1(0)$ & & \\
\hline \multicolumn{4}{|l|}{ Antiemetic class } \\
\hline Chemotherapy & $\begin{array}{l}\text { 5-HT3 } \\
\quad \text { antagonists } \\
\quad+\mathrm{NK} 1 \\
\quad \text { antagonists } \\
\quad N(\%)\end{array}$ & $\begin{array}{l}\text { 5-HT3 } \\
\text { antagonists } \\
\text { only } N(\%)\end{array}$ & $\begin{array}{l}\text { Other } \\
\qquad \begin{array}{l}N \\
(\%)\end{array}\end{array}$ \\
\hline Carboplatin-based & $11(13)$ & $74(86)$ & $1(1)$ \\
\hline Cisplatin-based & $82(83)$ & $13(13)$ & $4(4)$ \\
\hline Other & 0 & $2(67)$ & $1(33)$ \\
\hline
\end{tabular}


these proportions being quite similar at the following cycles. Likewise for anticipatory CINV, CINV occurrence over time was more frequently reported by women and younger patients (Table 2).
Pre-chemotherapy anxiety was reported by $167(89 \%)$ patients (mild 27\%; moderate 43\%; severe 19\%) and was more common in those experiencing also anticipatory CINV. Proportions of patients perceiving anxiety increased to $93 \%$

Table 2 Proportions of patients experiencing anticipatory CINV and acute/delayed CINV

T0

\begin{tabular}{|c|c|c|c|}
\hline & Anticipatory nausea $N(\%)$ & Anticipatory vomiting $N(\%)$ & Anticipatory CINV N (\%) \\
\hline Overall $(N=188)$ & $74(39)$ & $40(21)$ & $75(40)$ \\
\hline \multicolumn{4}{|l|}{ Gender } \\
\hline Male $(N=134)$ & $50(37)$ & $27(20)$ & $51(38)$ \\
\hline Female $(N=54)$ & $24(44)$ & $13(24)$ & $24(44)$ \\
\hline \multicolumn{4}{|l|}{ Age classes } \\
\hline $40-50(N=13)$ & $8(62)$ & $3(23)$ & $8(62)$ \\
\hline $50-60(N=32)$ & $13(41)$ & $5(16)$ & $13(41)$ \\
\hline $60-70(N=92)$ & $33(36)$ & $20(22)$ & $34(37)$ \\
\hline$>70(N=51)$ & $20(39)$ & $12(24)$ & $20(39)$ \\
\hline \multicolumn{4}{|l|}{$\mathrm{T} 1$} \\
\hline & Acute/delayed nausea $N(\%)$ & Acute/delayed vomiting $N(\%)$ & Acute/delayed CINV N (\%) \\
\hline Overall $(N=164)$ & $109(66)$ & $62(38)$ & $112(68)$ \\
\hline \multicolumn{4}{|l|}{ Gender } \\
\hline Male $(N=117)$ & $74(63)$ & $44(38)$ & $77(66)$ \\
\hline Female $(N=47)$ & $35(74)$ & $18(38)$ & $35(74)$ \\
\hline \multicolumn{4}{|l|}{ Age classes } \\
\hline $40-50(N=12)$ & $10(83)$ & $5(42)$ & $10(83)$ \\
\hline $50-60(N=30)$ & $22(73)$ & $15(50)$ & $23(77)$ \\
\hline $60-70(N=81)$ & $54(67)$ & $30(37)$ & $54(67)$ \\
\hline$>70(N=41)$ & $23(56)$ & $12(29)$ & $25(61)$ \\
\hline \multicolumn{4}{|l|}{$\mathrm{T} 2$} \\
\hline & Acute/delayed nausea $N(\%)$ & Acute/delayed vomiting $N(\%)$ & Acute/delayed CINV $N(\%)$ \\
\hline Overall $(N=138)$ & $98(71)$ & $45(33)$ & $98(71)$ \\
\hline \multicolumn{4}{|l|}{ Gender } \\
\hline Male $(N=98)$ & $65(66)$ & $26(27)$ & $65(66)$ \\
\hline Female $(N=40)$ & $33(83)$ & $19(48)$ & $33(83)$ \\
\hline \multicolumn{4}{|l|}{ Age classes } \\
\hline $40-50(N=10)$ & $9(90)$ & $4(40)$ & $9(90)$ \\
\hline $50-60(N=27)$ & $19(70)$ & $8(30)$ & $19(70)$ \\
\hline $60-70(N=68)$ & $47(69)$ & $23(34)$ & $47(69)$ \\
\hline$>70(N=33)$ & $23(70)$ & $10(30)$ & $23(70)$ \\
\hline \multicolumn{4}{|l|}{$\mathrm{T} 3$} \\
\hline & Acute/delayed nausea $N(\%)$ & Acute/delayed vomiting $N(\%)$ & Acute/delayed CINV $N(\%)$ \\
\hline Overall $(N=101)$ & $72(71)$ & $37(37)$ & $72(71)$ \\
\hline \multicolumn{4}{|l|}{ Gender } \\
\hline Male $(N=71)$ & $47(66)$ & $23(32)$ & $47(66)$ \\
\hline Female $(N=30)$ & $25(83)$ & $14(47)$ & $25(83)$ \\
\hline \multicolumn{4}{|l|}{ Age classes } \\
\hline $40-50(N=6)$ & $5(83)$ & $3(50)$ & $5(83)$ \\
\hline $50-60(N=18)$ & $17(94)$ & $9(50)$ & $17(94)$ \\
\hline $60-70(N=55)$ & $33(60)$ & $19(35)$ & $33(60)$ \\
\hline$>70(N=22)$ & $17(77)$ & $6(27)$ & $17(77)$ \\
\hline
\end{tabular}


at T1 (mild 41\%; moderate 39\%; severe 13\%), $90 \%$ at T2 (mild $43 \%$; moderate $38 \%$; severe $9 \%$ ), and $92 \%$ at T3 (mild $38 \%$; moderate $46 \%$; severe $8 \%$ ), thus quite stable also when compared with pre-chemotherapy anxiety. In addition, proportions of anxious patients were higher among those experiencing CINV at all the time points underlying a potential association between the two phenomena (Fig. 1).

Results about the degree of agreement between CvP, NvP, and $\mathrm{CvN}$ are shown in Table 3. Overall, $\mathrm{CvP}, \mathrm{NvP}$, and $\mathrm{CvN}$ agreements resulted to be moderate for the majority of the items considered.

The multivariate logistic model investigating the potential predictors of anticipatory CINV showed a statistically significant association between anticipatory CINV occurrence and anxiety experienced by patients before the first cycle of chemotherapy in all its mild, moderate, and severe manifestations. No association was detected for gender and age classes. Results from the GEE for repeated measures revealed that overall anxiety could effectively play a role in CINV development: a raising trend corresponding to increasing levels of anxiety was observed. Statistically significant association between CINV occurrence after chemotherapy start and anticipatory CINV was also detected. No association was found with gender, age classes, chemotherapy scheme, and anticipatory anxiety; however, despite missing the significance, the trend of the estimated ORs suggested an increased risk of developing CINV for women and patients undergoing cisplatin-based chemotherapy and a decreased risk for older patients (Table 4).

\section{Discussion}

Four major findings emerge from this survey: (1) the importance of symptom questionnaires during routine chemotherapy in lung cancer patients; (2) despite antiemetic prophylaxis, the proportion of patients experiencing both anticipatory and acute/delayed CINV is quite high; (3) CvP, NvP, and CvN agreements are moderate for the majority of the considered items; and (4) anxiety represents a strong predictor of nausea and vomiting.

Drawing comparisons with results from the literature is difficult due to the variability in study designs. However, a study by Cohen et al. reported that during cycle 1 of chemotherapy, only $33 \%$ of the patients had neither acute nor delayed CINV [9], which means patients experiencing acute and/or delayed CINV were about $67 \%$, thus in line with the results from the present study $(68 \%)$.

The agreement between patients and healthcare professionals was good for almost all the investigated items; this finding is in contrast with available data that often underline the gap between patients' and healthcare professionals' perceptions [10]. This difference could be explained as a positive response to Grunberg et al.'s trial data that revealed how medical staff underestimates the risk of CINV (particularly the delayed type) and concluded that educational program should be developed [5]. A study by Vidall et al. suggested that nausea severity and impact experienced by the patients were greater than perceived by physicians and oncology nurses; they also showed that healthcare professionals failed to distinguish between acute and delayed CINV [11]. Moreover, it is worth noting that for two items investigating aspects that are not objectively measurable (anxiety and mood), the agreement grade was almost always moderate, suggesting that a dialog between patients and healthcare professionals does exist. A good relationship with patients should be an important starting point to improve CINV-related outcomes and patients' QoL perception, with these aspects being highly correlated. Prechemotherapy anxiety showed to play a key role in the development of anticipatory CINV, and being anxious at the subsequent cycles increased the risk of acute/delayed CINV. Oncologists' and nurses' awareness about this issue could facilitate their intervention in relieving patients, with healthcare professionals not being just prescribers, but becoming caregivers in a more comprehensive way. The influence of anxiety on CINV development was observed in previous studies $[9,12]$, with the present survey further reinforcing evidences. In light of this, it is worth mentioning the emerging role of olanzapine. Primarily marketed as an antipsychotic,
Fig. 1 Patients experiencing anxiety stratified by CINV occurrence at T0, T1, T2, and T3

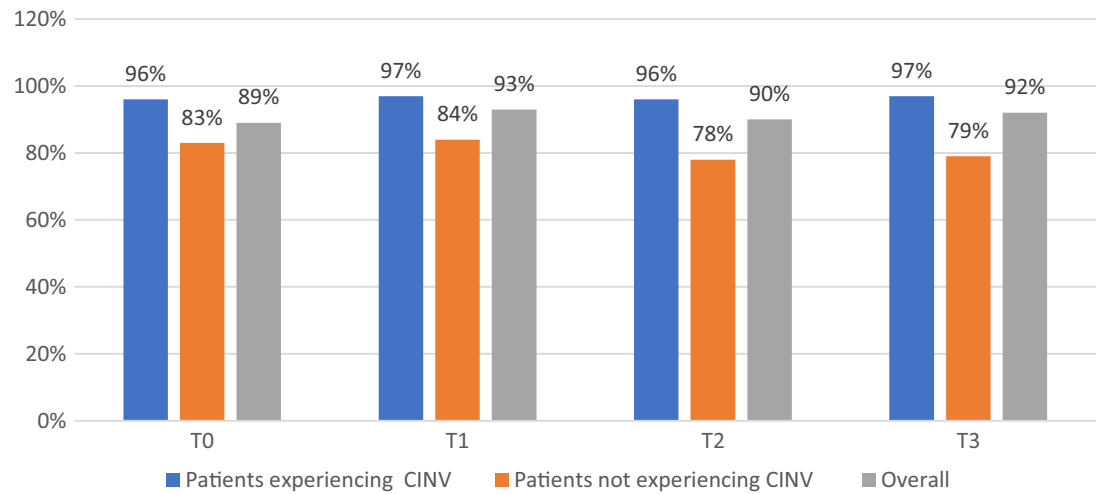


Table $3 \mathrm{CvP}$ and NvP agreement grade about the considered items at T0, T1, T2, and T3

\begin{tabular}{|c|c|c|c|c|}
\hline & \multicolumn{2}{|l|}{ Agreement grade } & \multicolumn{2}{|l|}{ Agreement grade } \\
\hline & $\begin{array}{l}\text { CvP } \\
\text { Kappa }[95 \% \text { CI]; grade }\end{array}$ & $\begin{array}{l}\text { NvP } \\
\text { Kappa }[95 \% \text { CI] }\end{array}$ & $\begin{array}{l}\text { CvP } \\
\text { Kappa }[95 \% \text { CI]; grade }\end{array}$ & $\begin{array}{l}\text { NvP } \\
\text { Kappa [95\% CI]; grade }\end{array}$ \\
\hline & Anxiety & & Pain & \\
\hline T0 & $0.51[0.43-0.59] ;$ moderate & $0.50[0.43-0.58] ;$ moderate & $0.51[0.44-0.59] ;$ moderate & $0.57[0.49-0.65] ;$ moderate \\
\hline $\mathrm{T} 1$ & $0.51[0.42-0.60] ;$ moderate & 0.48 [0.39-0.57]; moderate & 0.64 [0.57-0.71]; substantial & $0.62[0.54-0.70]$; substantial \\
\hline $\mathrm{T} 2$ & $0.36[0.26-0.46]$; fair & $0.49[0.40-0.59] ;$ moderate & $0.60[0.51-0.69] ;$ moderate & 0.58 [0.49-0.67]; moderate \\
\hline $\mathrm{T} 3$ & $\begin{array}{l}0.52[0.42-0.62] ; \text { moderate } \\
\text { Mood }\end{array}$ & $0.65[0.56-0.73] ;$ substantial & $\begin{array}{l}0.60[0.50-0.70] ; \text { moderate } \\
\text { Drowsiness }\end{array}$ & 0.72 [0.64-0.80]; substantial \\
\hline T0 & $0.45[0.37-0.54] ;$ moderate & $0.51[0.44-0.58] ;$ moderate & 0.38 [0.29-0.47]; fair & $0.52[0.44-0.60] ;$ moderate \\
\hline $\mathrm{T} 1$ & $0.49[0.41-0.58] ;$ moderate & $0.47[0.38-0.56] ;$ moderate & $0.52[0.43-0.60]$; fair & $0.56[0.47-0.64] ;$ moderate \\
\hline $\mathrm{T} 2$ & $0.38[0.27-0.49]$; fair & $0.54[0.44-0.64] ;$ moderate & $0.55[0.46-0.65] ;$ moderate & $0.62[0.53-0.72]$; substantial \\
\hline $\mathrm{T} 3$ & $\begin{array}{l}0.55[0.46-0.65] ; \text { moderate } \\
\text { Weakness }\end{array}$ & $0.60[0.50-0.70] ;$ moderate & $\begin{array}{l}0.47[0.36-0.59] ; \text { moderate } \\
\text { Breath }\end{array}$ & 0.67 [0.58-0.75]; substantial \\
\hline T0 & $0.38[0.29-0.46]$; fair & $0.46[0.39-0.54] ;$ moderate & $0.49[0.41-0.58] ;$ moderate & $0.54[0.46-0.61] ;$ moderate \\
\hline $\mathrm{T} 1$ & $0.44[0.36-0.52] ;$ moderate & $0.49[0.41-0.58] ;$ moderate & $0.60[0.52-0.67] ;$ moderate & $0.56[0.47-0.65] ;$ moderate \\
\hline $\mathrm{T} 2$ & $0.47[0.37-0.56] ;$ moderate & $0.53[0.44-0.61] ;$ moderate & $0.59[0.50-0.68] ;$ moderate & $0.51[0.40-0.61] ;$ moderate \\
\hline $\mathrm{T} 3$ & $\begin{array}{l}0.58[0.49-0.67] ; \text { moderate } \\
\text { Appetite }\end{array}$ & 0.57 [0.47-0.67]; moderate & $\begin{array}{l}0.57[0.47-0.68] ; \text { moderate } \\
\text { General condition }\end{array}$ & 0.68 [0.58-0.77]; moderate \\
\hline T0 & 0.38 [0.29-0.47]; fair & $0.45[0.36-0.54] ;$ moderate & 0.28 [0.19-0.38]; fair & 0.34 [0.25-0.44]; fair \\
\hline $\mathrm{T} 1$ & $0.50[0.41-0.59] ;$ moderate & $0.56[0.48-0.63] ;$ moderate & 0.28 [0.19-0.38]; fair & 0.29 [0.19-0.39]; fair \\
\hline $\mathrm{T} 2$ & $0.55[0.46-0.64] ;$ moderate & $0.53[0.43-0.64] ;$ moderate & 0.38 [0.28-0.48]; fair & $0.44[0.34-0.54] ;$ moderate \\
\hline $\mathrm{T} 3$ & $\begin{array}{l}0.50[0.39-0.61] ; \text { moderate } \\
\text { Nausea }\end{array}$ & $0.61[0.50-0.72] ;$ substantial & $\begin{array}{l}0.34[0.23-0.45] \text {; fair } \\
\text { Trust in treatments }\end{array}$ & 0.38 [0.26-0.49]; fair \\
\hline T0 & 0.32 [0.19-0.44]; fair & $0.41[0.30-0.53] ;$ moderate & $0.30[0.21-0.39]$; fair & $0.43[0.34-0.53] ;$ moderate \\
\hline $\mathrm{T} 1$ & $0.51[0.42-0.61] ;$ moderate & $0.60[0.51-0.69] ;$ moderate & 0.28 [0.18-0.39]; fair & $0.50[0.41-0.60] ;$ moderate \\
\hline $\mathrm{T} 2$ & $0.34[0.25-0.44]$; fair & $0.55[0.45-0.66] ;$ moderate & $0.45[0.35-0.55] ;$ moderate & $0.60[0.51-0.68] ;$ moderate \\
\hline $\mathrm{T} 3$ & $0.56[0.45-0.68] ;$ moderate & 0.68 [0.57-0.80]; substantial & $0.43[0.33-0.53] ;$ moderate & $0.60[0.49-0.71] ;$ moderate \\
\hline T0 & $\begin{array}{l}\text { Vomiting } \\
0.31[0.14-0.47] \text {; fair }\end{array}$ & $0.43[0.25-0.60] ;$ moderate & & \\
\hline $\mathrm{T} 1$ & 0.51 [0.39-0.62]; moderate & $0.61[0.51-0.72] ;$ substantial & & \\
\hline $\mathrm{T} 2$ & $0.60[0.48-0.72] ;$ moderate & $0.57[0.42-0.71] ;$ moderate & & \\
\hline $\mathrm{T} 3$ & $0.52[0.38-0.67] ;$ moderate & $0.60[0.44-0.76] ;$ moderate & & \\
\hline
\end{tabular}

olanzapine showed to improve QoL by allowing a better management of CINV when administered as an add-on therapy [13] also in platinum-based chemotherapy-naïve patients [14].

Likewise anxiety, also anticipatory CINV occurrence was a strong predictor of CINV, with this result in agreement with that from the study by Kim et al. where CINV in prior cycles was a strong predictor of CINV in subsequent cycles [15].

Contrary to what was expected, treatment with cisplatinbased chemotherapy was not significantly associated with a higher risk of developing CINV. The majority of patients receiving a cisplatin-based chemotherapy were treated with a 5HT3 and NK1 antagonist combination, while the proportion of patients administered with a carboplatin-based chemotherapy who received a 5-HT3 and NK1 antagonist combination was quite low, particularly at the first cycle. This result is probably linked to the fact that carboplatin is still being considered as a "less heavy" drug in the context of CINV by several oncologists. Recently, an update of MASSC and ESMO guidelines has recommended the administration of a 5-HT3 receptor antagonist in combination with dexamethasone and a NK1 receptor antagonist for the prevention of acute CINV also in patients receiving a carboplatin-based MEC [7]. A study by Kitazaki et al. concluded that triple therapy with aprepitant, palonosetron, and dexamethasone can be recommended for supporting both carboplatin-based and cisplatinbased chemotherapy [16]. In this study, the lack of a significant association between chemotherapy scheme and CINV occurrence could suggest that a correct management of patients receiving HEC could allow a control of CINV symptomatology in patients at higher risk of CINV that is even 
Table 4 Results from Multivariate Logistic Regression Model and GEE estimates for repeated measures

\begin{tabular}{|c|c|c|c|}
\hline \multirow[t]{2}{*}{ Covariates } & \multicolumn{3}{|c|}{ Multivariate Logistic Regression Model at T0 } \\
\hline & Odds ratio & {$[95 \% \mathrm{CI}]$} & $p$ value \\
\hline \multicolumn{4}{|l|}{ Gender } \\
\hline Female versus male & 1.0 & {$[0.5-1.9]$} & 0.88 \\
\hline \multicolumn{4}{|l|}{ Age classes } \\
\hline $50-60$ versus $40-50$ & 0.6 & {$[0.2-2.2]$} & 0.42 \\
\hline $60-70$ versus $40-50$ & 0.4 & {$[0.1-1.3]$} & 0.13 \\
\hline $70+$ versus $40-50$ & 0.5 & {$[0.1-1.9]$} & 0.31 \\
\hline \multicolumn{4}{|l|}{ Anxiety at $\mathrm{T} 0$} \\
\hline Mild versus absence & $5.0^{1}$ & {$[1.3-19.8]$} & 0.02 \\
\hline Moderate versus absence & $4.9^{1}$ & {$[1.3-18.5]$} & 0.02 \\
\hline Severe versus absence & $4.7^{1}$ & {$[1.1-20.0]$} & 0.04 \\
\hline \multicolumn{4}{|l|}{ GEE estimates for repeated measures } \\
\hline Covariates & Odds ratio & {$[95 \% \mathrm{CI}]$} & $p$ value \\
\hline \multicolumn{4}{|l|}{ Gender } \\
\hline Female versus male & 1.6 & {$[0.8-3.2]$} & 0.2 \\
\hline \multicolumn{4}{|l|}{ Age classes } \\
\hline $50-60$ versus $40-50$ & 0.6 & {$[0.2-2.2]$} & 0.45 \\
\hline $60-70$ versus $40-50$ & 0.5 & {$[0.1-1.5]$} & 0.20 \\
\hline $70+$ versus $40-50$ & 0.6 & {$[0.2-2.4]$} & 0.48 \\
\hline \multicolumn{4}{|l|}{ Anxiety at $\mathrm{T} 0$} \\
\hline Mild versus absence & 1.0 & {$[0.4-2.5]$} & 0.94 \\
\hline Moderate versus absence & 1.1 & {$[0.4-2.7]$} & 0.90 \\
\hline Severe versus absence & 0.9 & {$[0.3-2.7]$} & 0.81 \\
\hline \multicolumn{4}{|l|}{ Overall anxiety $^{2}$} \\
\hline Mild versus absence & $10.0^{1}$ & {$[3.3-30.6]$} & $<0.001$ \\
\hline Moderate versus absence & $11.2^{1}$ & {$[3.5-35.7]$} & $<0.001$ \\
\hline Severe versus absence & $12.9^{1}$ & {$[2.8-58.5]$} & $<0.001$ \\
\hline \multicolumn{4}{|l|}{ Anticipatory CINV } \\
\hline Presence versus absence & $2.3^{1}$ & {$[1.2-4.3]$} & 0.01 \\
\hline \multicolumn{4}{|l|}{ Chemotherapy scheme } \\
\hline Cisplatin-based versus carboplatin-based & 1.8 & {$[1.0-3.2]$} & 0.07 \\
\hline
\end{tabular}

GEE generalized equation estimates, CINV chemotherapy-induced nausea and vomiting

${ }^{1}$ Statistically significant based on $95 \%$ confidence intervals and $p$ values

${ }^{2}$ Anxiety level based on the mean of ratings assigned to the item anxiety at T1, T2, and T3

better than that achieved in patients at lower risk but not receiving a combination of 5-HT3 and NK1 receptor antagonists. Under this perspective, adherence to updated guidelines, the necessity for healthcare professionals to be always aware of improvement in pharmacology treatments is fundamental.

Finally, according to recent literature data, this study highlighted the decisive role of questionnaires assessing symptoms during treatment of advanced cancers to identify early adverse events and to improve symptom management $[17,18]$. The use of patient-reported outcomes (PROs) in clinical practice to improve QoL and manage toxicity should be encouraged particularly considering results from the recent study by Basch. In fact, Basch and colleagues reported an increase of overall survival in association with the adoption of electronic patient-reported symptom monitoring [19]. Furthermore, Basch suggested that patient-reported data could be used in several areas (as to improve the management of post-chemotherapy nausea or to identify unexpected symptoms associated with a particular drug) to turn the rhetoric regarding "patient-centered care" into a reality [20].

Our study represents a further confirmation about the importance of collecting PROs, with "patients' voices" having allowed us to detect the strong link between anxiety and CINV. This result can stimulate the conduction of new trials to refine the management of this symptom and, indirectly, of CINV. 
A strength of the present study was the homogeneity of the sample in terms of type of neoplasia, stage, chemotherapy line, treatment, and adherence to guidelines. Similarly, the simultaneous assessment of physicians', nurses', and patients' perception and their comparison constituted a strength.

Furthermore, the proportion of duly compiled questionnaire was very high, probably reflecting the interest in the investigated issue and ensuring accuracy of data collected. The number of patients taking part to the survey was not very high, although, the implementation of GEE for repeated measures allowed handling of missing data without excluding patients lost to follow-up [21].

The most relevant result emerging in this study is therefore the key role of anxiety and its link with CINV development. It follows that a better assessment and management of anxiety could improve CINV control through close cooperation among healthcare professionals and advocacy patients.

\section{Conclusion}

Even if clinical staff was aware and sensitive about patients' status and perceptions, CINV is still representing a problem among patients undergoing chemotherapy. This study further confirms that physicians and nurses should pay particular attention to anxiety due to its key role in CINV development.

\section{Compliance with ethical standards}

Conflict of interest SN has been a speaker bureau for Eli Lilly, Roche, Merck Sharp \& Dohme, Bristol Myers Squibb, Boehringer Ingelheim, and Astra Zeneca. VP and NC are Quintiles IMS employees. All remaining authors have declared no conflicts of interest.

\section{References}

1. Sommariva S, Pongiglione B, Tarricone R (2016) Impact of chemotherapy-induced nausea and vomiting on health-related quality of life and resource utilization: a systematic review. Crit Rev Oncol Hematol 99:13-36. https://doi.org/10.1016/j.critrevonc. 2015.12.001

2. Ihbe-Heffinger A, Ehlken B, Bernard R, Berger K, Peschel C, Eichler HG, Deuson R, Thödtmann J, Lordick F (2004) The impact of delayed chemotherapy-induced nausea and vomiting on patients, health resource utilization and costs in German cancer centers. Ann Oncol 15(3):526-536. https://doi.org/10.1093/annonc/mdh110

3. Grunberg SM, Deuson RR, Mavros P, Geling O, Hansen M, Cruciani G, Daniele B, de Pouvourville G, Rubenstein EB, Daugaard G (2004) Incidence of chemotherapy-induced nausea and emesis after modern antiemetics. Cancer 100(10):2261-2268. https://doi.org/10.1002/cncr.20230

4. MASSC/ESMO. MASSC (2016) [Online] [Cited: July 27, 2016] http://www.mascc.org/antiemetic-guidelines

5. Lorusso V (2016) Management of chemotherapy-induced nausea and vomiting by risk profile: role of netupitant/palonosetron. Ther
Clin Risk Manag 12:917-925. https://doi.org/10.2147/TCRM. S89215

6. Molassiotis A, Aapro M, Dicato M, Gascon P, Novoa SA, Isambert N, Burke TA, Gu A, Roila F (2014) Evaluation of risk factors predicting chemotherapy-related nausea and vomiting: results from a European prospective observational study. J Pain Symptom Manag 47(5):839-848. https://doi.org/10.1016/j.jpainsymman. 2013.06.012

7. Basch E, Prestrud AA, Hesketh PJ, Kris MG, Feyer PC, Somerfield MR, Chesney M, Clark-Snow RA, Flaherty AM, Freundlich B, Morrow G, Rao KV, Schwartz RN, Lyman GH, American Society of Clinical Oncology (2011) American Society of Clinical OncologyAntiemetics: American Society of Clinical Oncology clinical practice guideline update. J Clin Oncol 29(31):41894198. https://doi.org/10.1200/JCO.2010.34.4614

8. Landis JR, Koch GG (1977) The measurement of observer agreement for categorical data. Biometrics 33(1):159-174. https://doi. org $/ 10.2307 / 2529310$

9. Cohen L, de Moor CA, Eisenberg P, Ming EE, Hu H (2007) Chemotherapy-induced nausea and vomiting: incidence and impact on patient quality of life at community oncology settings. Support Care Cancer 15(5):497-503. https://doi.org/10.1007/s00520-0060173-Z

10. Di Maio M, Gallo C, Leighl NB, Piccirillo MC, Daniele G, Nuzzo F, Gridelli C, Gebbia V, Ciardiello F, de Placido S, Ceribelli A, Favaretto AG, de Matteis A, Feld R, Butts C, Bryce J, Signoriello S, Morabito A, Rocco G, Perrone F (2015) Symptomatic toxicities experienced during anticancer treatment: agreement between patient and physician reporting in three randomized trials. J Clin Oncol 33(8):910-915. https://doi.org/10.1200/JCO.2014.57.9334

11. Vidall C, Fernández-Ortega P, Cortinovis D, Jahn P, Amlani B, Scotté F (2015) Impact and management of chemotherapy/ radiotherapy-induced nausea and vomiting and the perceptual gap between oncologists/oncology nurses and patients: a cross-sectional multinational survey. Support Care Cancer 23(11):3297-3305. https://doi.org/10.1007/s00520-015-2750-5

12. Molassiotis A, Lee PH, Burke TA, Dicato M, Gascon P, Roila F, Aapro M (2016) Anticipatory nausea, risk factors, and its impact on chemotherapy-induced nausea and vomiting: results from the Pan European Emesis Registry study. J Pain Symptom Manag 51(6): 987-993. https://doi.org/10.1016/j.jpainsymman.2015.12.317

13. Chow R, Chiu L, Navari R, Passik S, Chiu N, Popovic M, Lam H, Pasetka M, Chow E, DeAngelis C (2016) Efficacy and safety of olanzapine for the prophylaxis of chemotherapy-induced nausea and vomiting (CINV) as reported in phase I and II studies: a systematic review. Support Care Cancer 24(2):1001-1008. https://doi. org/10.1007/s00520-015-3000-6

14. Mukhopadhyay S, Kwatra G, Alice KP, Badyal D (2017) Role of olanzapine in chemotherapy-induced nausea and vomiting on platinum-based chemotherapy patients: a randomized controlled study. Support Care Cancer 25(1):145-154. https://doi.org/10. 1007/s00520-016-3386-9

15. Kim HK, Hsieh R, Chan A et al (2015) Impact of CINV in earlier cycles on CINV and chemotherapy regimen modification in subsequent cycles in Asia Pacific clinical practice. Support Care Cancer 23(1):293-300. https://doi.org/10.1007/s00520-014-2376-Z

16. Kitazaki T, Fukuda Y, Fukahori S, Oyanagi K, Soda H, Nakamura Y, Kohno S (2015) Usefulness of antiemetic therapy with aprepitant, palonosetron, and dexamethasone for lung cancer patients on cisplatin-based or carboplatin-based chemotherapy. Support Care Cancer 23(1):185-190. https://doi.org/10.1007/ s00520-014-2339-4

17. Stover AM, Basch EM (2017) The potential role of symptom questionnaires in palliative and supportive cancer care delivery. Curr Oncol Rep 19(2):12. https://doi.org/10.1007/s11912-017-0571-z 
18. Mendoza TR, Dueck AC, Bennett AV, Mitchell SA, Reeve BB, Atkinson TM, Li Y, Castro KM, Denicoff A, Rogak LJ, Piekarz RL, Cleeland CS, Sloan JA, Schrag D, Basch E (2017) Evaluation of different recall periods for the US National Cancer Institute's PRO-CTCAE. Clin Trials 14(3):255-263. https://doi.org/10.1177/ 1740774517698645

19. Basch E, Deal AM, Dueck AC et al (2017) Overall survival results of a trial assessing patient-reported outcomes for symptom monitoring during routine cancer treatment. JAMA 318(2):197-198
20. Basch E (2017) Patient-reported outcomes - harnessing patients' voices to improve clinical care. N Engl J Med 376(2):105-108

21. Ma Y, Mazumdar M, Memtsoudis SG (2012) Beyond repeated measures ANOVA: advanced statistical methods for the analysis of longitudinal data in anesthesia research. Reg Anesth Pain Med 37(1):99-105. https://doi.org/10.1097/AAP.0b013e31823ebc74 